\title{
Social Capital, Socioeconomic Status and Self-efficacy
}

\author{
Jing $\mathrm{Han}^{1}$, Xiaoyuan $\mathrm{Chu}^{1}$, Huicun Song ${ }^{2}$, Yuan $\mathrm{Li}^{3}$ \\ ${ }^{1}$ School of Economics and Resource Management, Beijing Normal University, Beijing, China \\ ${ }^{2}$ School of Humanity and Law, Beijing University of Civil Engineering and Architecture, Beijing, China \\ ${ }^{3}$ Research Department, CIConsulting, Shenzhen, China \\ Correspondence: Xiaoyuan Chu, School of Economics and Resource Management, Beijing Normal University, Beijing, \\ China.E-mail: seancxy@126.com
}

Received: October 27, 2014

Accepted: November 11, $2014 \quad$ Available online: December 11, 2014

doi:10.11114/aef.v2i1.607

URL: http://dx.doi.org/10.11114/aef.v2i1.607

\begin{abstract}
This study internalized social capital on the basis of traditional study of the influence of economic factors on self-efficacy, and studied the relationship among the family socio-economic status, social capital and self-efficacy. Based on the theoretical analysis, with first-hand data collection and using multiple regression models, the paper studied the intermediate effect of social capital in the relationship between the socioeconomic status and self-efficacy. We draw on the following conclusions: (1) The family socio-economic status as well as all its dimensions (father's degree of education, mother's degree of education, the total annual income of the family, father's occupation, mother's occupation) is significantly positively related to social capital and all the dimensions of its proxy variable (peer support, kinship support and general support of others); (2) There is a significant positive correlation between the family socio-economic status as well as all its dimensions and self-efficacy; the socio-economic status, with its dimensions, is the predictive variable of self-efficacy; (3) Social capital, with dimensions of its proxy variable, is positively correlated with self-efficacy and has predictive effect on self-efficacy (4) Social capital plays a significant intermediate role between socio-economic status and self-efficacy, and the mediating effect size is about $51.75 \%$.
\end{abstract}

Keywords: Socio-economic Status; Social Capital; Self-efficacy; Mediate Effect

\section{Introduction}

Self-efficacy is an individual's anticipation of one's ability to be in control under a particular situation. It plays an intermediate role between cognition and behavior, which reflects an individual's perception and confidence of his ability to complete specific tasks and reach particular goals. In another word, self-efficacy is the belief that an individual has in one's power to plan and take action to reach particular goals. Self-efficacy directly influences an individual's estimate of one's present situation and future ambition. Further, this estimate will be proved through self-prophecy in one's choice and performance in study, work and life.

The concept of social capital, first proposed by French scholar Bourdieu in 1970s and further developed by such scholars as Coleman, Portes, Putnam, Lin. N etc., has become a systematic theory and been applied to many fields. For example, in micro-field it is discovered that social capital can significantly improve economic growth (Knack \& Keefer, 1997; Temple \& Johnson, 1998; Zak \& Knack, 2001), promote financial development (Guiso, Sapienza \& Zingales, 2004), promote innovation (Akcomak \& Weel, 2009), enhance governmental efficiency (Deng, Y, and Gong, 2012). On the other hand, social capital research in micro-field remains relatively fewer, which, however, provides a new thought for social capital study. For example, social capital contributes to entrepreneurial self-efficacy (Chen \& He, 2011; Yang $\& \mathrm{Hu}, 2011,2013)$, political self-efficacy (Pei, 2013) and so on.

Socioeconomic Status (SES), a measurement of family members' social and economic status, is a kind of hierarchy made according to the amount of social resources an individual can obtain or control. The social resources usually include such factors as degree of education, income level and occupational reputation. Previous researches indicate that SES is closely correlated with social capital. For example, the researches on the subjects of study as private entrepreneurs (Bian \& Qiu, 2000), urban and rural residents (Zhang \& Ruan, 1999), trans-national migration (Wang, 2000), senior citizens (He, 2002), flowing farmers (Cao, 2003; Wang \& Tong, 2004) have proved the correlation between social capital and social status. In addition, other researches have proved social capital influences the 
subjective evaluation of one's SES as well as one's objective SES (Zhang \& Chen , 2012).

There are comparatively fewer researches of the relationship between SES and self-efficacy, but, according to the study on the relationship between the three dimensions of SES and self-efficacy, the research conclusion shows no difference: SES is positively correlated with self-efficacy. For example, family SES (Y. Li, 2007; X. Li, 2003), parents' degree of education (Chen, 2011; Yang, 2010) and parents' occupation (Li, 2003) have a positive correlation with children's self-efficacy (Liu, 2009).

In this study, we establish an analytical framework for SES, social capital and self-efficacy to analyze their relationships.

We hypothesize the following:

First, both social capital and SES have some effect on self-efficacy.

Second, SES has some effect on social capital.

Third, social capital is a mediator between SES and self-efficacy.

$$
\begin{gathered}
S E=\beta_{0}+\sum \lambda_{1} S E S+\sum \lambda_{2} C V+\varepsilon \\
S E=\beta_{0}+\sum \lambda_{3} S C+\sum \lambda_{4} C V+\varepsilon \\
S C=\beta_{0}+\sum \lambda_{5} S E S+\sum \lambda_{6} C V+\varepsilon \\
S E=\beta_{0}+\sum \lambda{ }^{\prime}{ }_{1} S E S+\sum \lambda{ }^{2} S C+\sum \lambda_{5} C V+\varepsilon
\end{gathered}
$$

With $\lambda_{1}, \lambda_{3}, \lambda_{5}$ are significant; and compared with $\lambda_{1}$, the statistical significance level of $\lambda^{\prime} 1$ drops significantly. Where SE is short for self-efficacy, SES is short for Socioeconomic status, SC is short for social capital, CV is short for control variable.

The hypothesis of this study is shown in figure 1: Socioeconomic status as a kind of environmental factor has both direct and indirect influence on self-efficacy, while the indirect influence works through social capital.

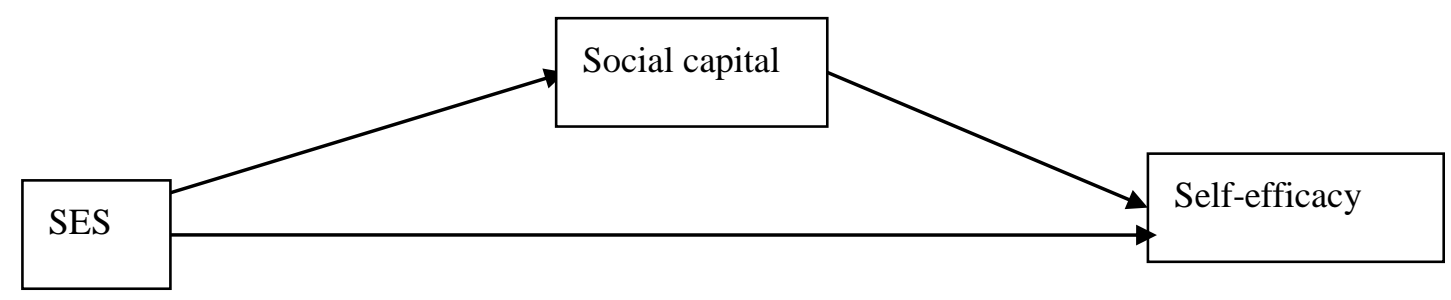

Figure 1. Theoretical Relationship among SES, SC and SE

\section{Methodology}

\subsection{Subjects of Study}

Cluster sampling methods were used for the investigation. 600 questionnaires were distributed to high school students aged $12-18$ from two senior high schools chosen in Beijing, with 541 questionnaires returned and 520 valid (male 226, female 294). The valid response rate is 86.67 .

\subsection{Research Instrument}

The definitions of variables and data sources are shown in table 1. Specific measuring tools are as follow:

SES: the index of family SES is often measured by parents' occupation, degree of education and family income. With reference to previous studies, this research applied a self-designed self-reporting questionnaire which divided parents' occupation into 5 grades, parents' degree of education into 6 grades and family income into 6 grades.

Social Capital: This research used social support appraisals (SS-A) scale (made by Vaux et al., and revised by (Xin, Chi, Geng, Zhao \& Wang, 2007) to measure social capital. 20 items in total in this scale respectively measured family or family member support, peer support and general support of others. 0.91 is the coefficient of the whole scale, in which $0.84,0.81$ and 0.83 are respectively the coefficients of family support ( 7 items), peer support ( 7 items), general support 
of others. ${ }^{1}$

Self-efficacy: Chinese version of General self-efficacy scale (designed by Jerusalem et al. and translated and revised by Wang, Hu \& Liu, 2001) was used to measure self-efficacy. This scale consists of 10 items and uses Likert four points scoring, which has good reliability. Its coefficient of internal consistency Cronbach is 0.87 , test-retest reliability is $0.83(\mathrm{p}<0.001)$, split-half reliability is $0.82(\mathrm{p}<0.001){ }^{2}$

Table 1. Definitions of Variables and Data Sources

\begin{tabular}{|c|c|c|c|c|}
\hline Variable & Name & $\begin{array}{l}\text { Operational Definition/ Proxy } \\
\text { Variable }\end{array}$ & scale & dimension \\
\hline Explained variables & SE & General self-efficacy scale score & $\begin{array}{l}\text { Chinese version of General } \\
\text { self-efficacy scale }\end{array}$ & null \\
\hline $\begin{array}{c}\text { Control variables } \\
(\mathrm{CV})\end{array}$ & Gender & null & null & null \\
\hline Explanatory variables & SES & $\begin{aligned} \mathrm{SES}= & (\mathrm{FE}+\mathrm{ME}+2 * \mathrm{FAI} \\
& +\mathrm{FO}+\mathrm{MO}) / 6\end{aligned}$ & Self-designed questionnaire & $\begin{array}{l}\text { FE; ME; FAI; } \\
\text { FO;MO }\end{array}$ \\
\hline Mediator variable & $\mathrm{SC}$ & $\mathrm{SS}=(\mathrm{FS}+\mathrm{PS}+\mathrm{GSO}) / 3$ & $\begin{array}{l}\text { Social support appraisals } \\
\text { scale }\end{array}$ & FS; PS; GSO \\
\hline
\end{tabular}

SES is short for socioeconomic status; FE is short for father's score of degree of education; ME is short for mother's score of degree of education; FAI is short for score of family annual income; FO is short for father's occupation; MO is short for mother's occupation; SC is short for social capital; SS is short for score of social support; FS is short for score of family support; PS is short for score of peer support; GSO is short for General support of others. the same below

\subsection{Research Process}

The questionnaires were administrated with the whole class as a group, employing group measurement under unified instructions. And the questionnaires, with no time limitation, were collected on the spot and checked one by one with invalid ones eliminated. This research employed SPSS19.0 for statistical analysis, which includes analysis of variance, correlation analysis and analysis of regression.

\section{Results}

\subsection{Reliability of the Questionnaire}

We undertook item analysis to calculate the reliability of the questionnaire/ scale for SES, social capital and SE and the coefficient Conbach $\alpha$ is in table 2 as below:

The data in table 2 shows that all the three questionnaires of SES, social capital and SE are reliable with reliability above 0.8 .

\subsection{Correlation Analysis and Regression Analysis}

Pearson's correlation is applied to calculate the correlation coefficients of the SES as well as its dimensions, SC as well as its dimensions and SE. The result in table 2 shows that there is a significantly positive correlation between SES as well as its dimensions and SC as well as its dimensions, with the correlation coefficients between 0.132 to 0.277 (the correlation coefficient between the SES and SE is 0.277). This means that there is a significantly positive correlation between the SES and SC of the sample group.

There is a significantly positive correlation between SES as well as its dimensions and SE, and the correlation coefficients are between 0.131 to 0.214 (correlation coefficient between the SES and SE is 0.214). This means that SES is significantly positively correlated to SE.

There is a significantly positive correlation between SC with its dimensions and SE, and the correlation coefficients are between 0.287 to 0.400 (correlation coefficient between SC total score and SE is 0.398), which means that SE is significantly positively correlated to SC.

\footnotetext{
${ }^{1}$ XIN Zi-Qiang, CHI Li-Ping, GENG Liu-Na,et al. Revision and Application of the Social Support Appraisal Scale. Chinese Mental Health Journal, 2007, 6: 379-381

${ }^{2}$ WANG Caikang HU Zhongfeng LIU Yong, Evidences for Reliability and Validity of the Chinese Version of General Self Efficacy Scale, Chinese Journal of Applied Psychology, 2001,(01): 37-40
} 
Table 2. Correlation Coefficients and Cronbach's Alpha of the SES, SC and SE

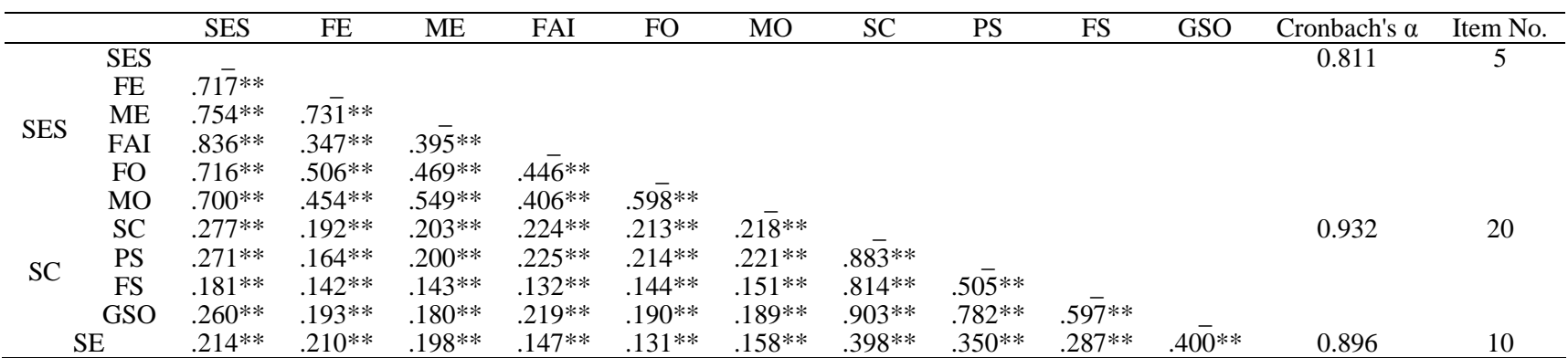

Note: $* * * * *$ and $*$ indicate that the coefficient is significant at the $0.01,0.05$ and 0.1 levels, respectively the same below.

To further explore the relationship among SES, SC and SE, regression analysis is made so as to study the predictability of family SES and SC on SE.

Using simple regression analysis with SC and SE as predicted variable respectively, this research discussed the influence and predictive effect of SES as well as its dimensions on SC and SE. The result is shown in table 3:

It is revealed that SES and its dimensions (father's degree of education, mother's degree of education, family annual income, father's occupation and mother's occupation) are all predictive variables of SE, the explained variables are respectively $4.4 \%, 4.2 \%, 3.7 \%, 2.0 \%, 1.5 \%$ and $2.3 \%$. Meanwhile, SES and all its dimensions are the predicative variables of SC, and the explained variables are respectively $7.5 \%, 3.5 \%, 3.9 \%, 4.8 \%, 4.4 \%$ and $4.6 \%$, which are higher than the influence of SES and its dimensions on SE, except father's degree of education. It means that SES and its dimensions have less influence on SE than that on SC. In addition, SES total score and its dimensions exert influence on $\mathrm{SE}$ and SC in the same direction. In another word, with the improvement of SES, SE as well as SC increases.

Table 3. Simple Regression of SES and Its Dimension on SC and SE

\begin{tabular}{cccccc}
\hline Predicted variable & Predictive variable & $R^{2}$ & Adjusted $R^{2}$ & $\beta$ & $T$ \\
\hline \multirow{5}{*}{ SE } & SES & 0.046 & 0.044 & 0.214 & $4.997 * * *$ \\
& FE & 0.044 & 0.042 & 0.210 & $4.884 * * *$ \\
& ME & 0.039 & 0.037 & 0.198 & $4.588 * * *$ \\
& FAI & 0.022 & 0.020 & 0.147 & $3.388 * *$ \\
& FO & 0.017 & 0.015 & 0.131 & $3.003 * *$ \\
& MO & 0.025 & 0.023 & 0.158 & $3.641 * * *$ \\
& SES & 0.076 & 0.075 & 0.277 & $6.537 * * *$ \\
SC & FE & 0.037 & 0.035 & 0.192 & $4.439 * * *$ \\
& MO & 0.041 & 0.039 & 0.203 & $4.711 * * *$ \\
& FAI & 0.050 & 0.048 & 0.224 & $5.224 * * *$ \\
& FO & 0.045 & 0.044 & 0.213 & $4.957 * * *$ \\
& MO & 0.048 & 0.046 & 0.218 & $5.084 * * *$ \\
\hline
\end{tabular}

To better reveal the relationship among SES, SC and SE, we took social capital as well as three dimensions of its proxy variable and SE as the dependent variables and dimensions of SES as the independent variable, and conducted a stepwise regression analysis. As can be seen from table 4:

Mother's occupation is a positive predictor of peer support, family support and social capital; family annual income is a positive predictor of peer support, general support of others and social capital. And father's degree of education is the only positive predictor of SE. It means the higher father's degree of education is, the higher his children's SE is.

Table 4. Stepwise Regression Analysis of Dimensions of SES on Dimensions of SC and SE

\begin{tabular}{cccccc}
\hline Predicted variable & Predictive variable & $R^{\mathbf{2}}$ & Adjusted $R^{\mathbf{2}}$ & $\beta$ & $T$ \\
\hline PS & FAI & 0.051 & 0.049 & 0.162 & $3.494^{* *}$ \\
& MO & 0.071 & 0.067 & 0.155 & $3.336^{* *}$ \\
FS & MO & 0.023 & 0.021 & 0.151 & $3.473 * *$ \\
GSO & FAI & 0.048 & 0.046 & 0.173 & $3.791 * * *$ \\
& FE & 0.063 & 0.060 & 0.132 & $2.910^{* *}$ \\
SC & FAI & 0.050 & 0.048 & 0.162 & $3.487 * *$ \\
& MO & 0.070 & 0.066 & 0.153 & $3.280^{* *}$ \\
SE & FE & 0.044 & 0.042 & 0.210 & $4.884 * *$ \\
\hline
\end{tabular}


Applying the same analysis method, we conducted a simple regression analysis with SE as predicted variable while SC and dimensions of its proxy variable as predictive variable, and the result is as shown in table 5: SC and dimensions of its proxy variable (peer support, family support and General support of others) all have predictive effect on SE, with respective explained variance $15.6 \%, 12.0 \%, 8.1 \%$ and $15.8 \%$. And among the three dimensions, general support of others has the strongest influence. From the perspective of directivity, SC and dimensions of its proxy variable changed along the same direction, in another word, SC and the three dimensions of its proxy variable all have statistically significant enhancement effect on SE.

Table 5. Simple Regression of SC and Dimensions of Its Proxy Variable on SE

\begin{tabular}{ccccc}
\hline Predictive variable & $R^{2}$ & Adjusted $R^{2}$ & $\beta$ & $T$ \\
\hline SC & 0.158 & 0.156 & 0.398 & $9.840 * * *$ \\
PS & 0.122 & 0.120 & 0.350 & $8.482 * * *$ \\
FS & 0.083 & 0.081 & 0.287 & $6.829 * * *$ \\
GSO & 0.160 & 0.158 & 0.400 & $9.928 * * *$ \\
\hline
\end{tabular}

Applying multiple stepwise regression analysis and taking dimensions of the proxy variable of SC as predictive variables, we explored the influence and predictive effect of dimensions of SC on SE. As can be seen from table 6, only general support of others is effective predictor of SE. And it has a significantly positive predicative effect on SE, with $16 \%$ of variance be explained.

Table 6. Stepwise Regression of Dimensions of the Proxy Variable of SC on SE

\subsection{Pathway Analysis}

\begin{tabular}{ccccc}
\hline Predictive variable & $R^{2}$ & Adjusted $R^{2}$ & $\beta$ & $T$ \\
\hline GSO & 0.161 & 0.160 & 0.402 & $9.959 * * *$ \\
\hline
\end{tabular}

Multiple regression was employed to study the prediction of SES on SC, and the result is shown in table 7: step 1, simple linear regression was conducted with gender as the control variable and SC as the dependent variable; step 2, multiple regression analysis was conducted with gender as the control variable, SES as the independent variable and SC as the dependent variable. The result shows that SC has a positive predicative effect on SC with the influence of gender in consideration.

Table 7. Multiple Regression Analysis of SC

\begin{tabular}{cccccccc}
\hline \multicolumn{2}{c}{ Variable } & \multicolumn{3}{c}{ First-step } & \multicolumn{3}{c}{ Second-step } \\
\hline & & B & SE & $\beta$ & B & SE & $\beta$ \\
CV & Gender & 0.162 & 0.063 & $0.112 *$ & 0.184 & 0.061 & $0.127 * *$ \\
Predictor & SES & & & & 0.033 & 0.005 & $0.283^{* * *}$ \\
\hline
\end{tabular}

Note: gender is dummy variable, and boy $=1$, girl $=2$, the same below

In accordance with the mechanism of mediator, we tested the intermediation of SC in the relationship between SES and SE. Step 1, simple linear regression was conducted with gender as the control variable and SE as the dependent variable; step 2, multiple regression analysis was conducted with gender as the control variable, SES as the independent variable and SE as the independent variable; step 3, multiple regression analysis was conducted with SC as the mediate variable on the basis of the control variable, the independent variable and the dependent variable as that of step 2 . The result is shown in table 8:

Table 8. Multiple Regression Analysis of SE

\begin{tabular}{ccccccccccc}
\hline \multicolumn{2}{c}{ Variable } & \multicolumn{3}{c}{ First-step } & \multicolumn{3}{c}{ Second-step } & \multicolumn{3}{c}{ Third-step } \\
\hline & & B & SE & $\beta$ & B & SE & $\beta$ & B & SE & $\beta$ \\
CV & Gender & -1.097 & 0.531 & $-0.090 *$ & -0.956 & 0.520 & -0.079 & -1.549 & 0.489 & $-0.127 * *$ \\
Predictor & SES & & & & 0.208 & 0.042 & $0.210 * * *$ & 0.100 & 0.041 & $0.101 *$ \\
Mediator & SC & & & & & & & 3.219 & 0.351 & $0.384 * * *$ \\
\hline
\end{tabular}

With the mediator (social capital) taken in the regression function, the regression coefficient of SES on SE changed from statistical significant in 0.001 level to statistical insignificant in 0.01 level (although still significant in 0.05 level), which reveals that SC is a significant partial mediator between SES and SE, as shown in the figure 2: 
$\mathrm{C}=0.210$
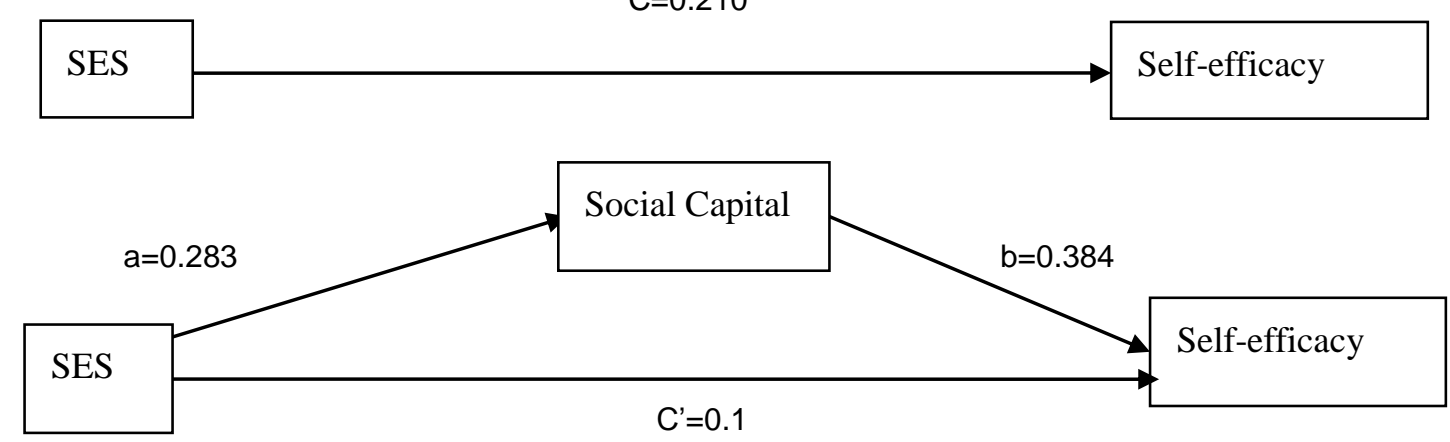

Figure 2. Mediating Effect of SC on SES and SE

The size of mediating effect is: $0.283 * 0.384 / 0.210=51.75 \%$

\section{Discussion}

\subsection{The Influence of SES, SC on SE}

We find that both SES and SC significantly positively correlated with SE, which provides some proofs for the influence factors of SE from empirical study.

As for the relationship between SC and family SES, the SC an individual can use is influenced by one's family SES: one with higher SES owns more social capital. This can be reflected from support from family, peer and general others. One possible reason is that those with low SES do not have much opportunity for social learning of exchange and acquisition of social capital. Another possible reason is unequal primary allocation of SC to certain extent determined by SES affected the establishment and accumulation of SC thereafter. This conclusion is consistent with previous studies (Lianne \& David, 1999; Thomas, 1990; Wight, 2006).

As for SES and SE, An individual's family SES has a significantly positive correlation with one's SE. Thus it is concluded that family SES can influence SE, which is in line with the researches of Chen Xianli (2011), Li Xiaojuan (2003) and so on. Family SES influences SE in the following ways: first, the social resources that the family owns influences SE; second, family SES influences SE through the expectations from people around and subjects themselves; third, family SES influences SE through corresponding social roles. Finally, as what we found in this study, family SES influences SE through the SC that one can make use of. During stepwise regression analysis, it is revealed that only father's education of degree came into the regression equation of SE and had the predicative effect on SE, which means that the higher the father's degree of education is, the higher the subject's SE is. In another word, father's degree of education is very important among the predicative factors of SE.

As for SC and SE, SC and all the dimensions of its proxy variable (peer support, family support and general support of others) have predicative effect on SE. This conclusion is in line with those of Gao Bingcheng (2010), Hu Ping (2009) and so on, and also validates our hypothesis: SE will be higher with more SC. The relationship between SC and SE can be accounted for in the following ways: first, one important influence factor of SE is one's direct experience, which includes experience related to interpersonal communication. The available amount of SC for subjects influences their feedback about themselves and sense of competence. In other words, SC has a direct influence on one's SE, which is significant no matter in family relations, peer relations and general relations with others. Second, verbal persuasion is one of the influence factors of SE. People owning different amount of SC would receive different amount of positive persuasion. Subjects with more SC are more likely to receive encouragement and consent, which will also enhance their SE. Finally, apart from the competence of oneself, one with more social capital, facing problems, are more likely to seek solutions via social network, which enhances the SE to some degree. When stepwise regression is conducted, it is found that only general support from others came into the function with the SE as the predicted variable. And it has significantly positive predicative effect on SE with $16 \%$ explanation of variance. Chances are that general support of others is more steady and general than family support or peer support, which can better reflect the SC one owns.

\subsection{The Mediating Effect of SC on SES and SE}

The mechanism of mediating effect of SC on SES and SE (figure 2) reveals that SES has a direct influence on SE, and 
in the meantime, has an indirect influence on SE via social capital. And in the relation between SES and SE, the mediating effect size of SC is up to $51.75 \%$, which means that social capital, as a partial mediator, plays a very important role in the process of SES influencing SE. In another word, family SES influences one's SE, to a large extent, by impacting their amount of social capital. To be specific, subjects from families with better SES are more likely to receive more social capital, so they have higher SE; on the contrary, subjects from families with lower SES are more likely to have lower SE due to their limited amount of social capital. In other words, family SES's promoting effect on SE is not fulfilled entirely in a direct way, but partially depends on the amount of social capital.

\subsection{Suggestion}

The conclusion of this study validates our hypothesis, i.e. in the course of SES influencing SE, SC plays a mediate role. This finding preliminarily reveals how SES influences SE, i.e. its specific influencing process and mechanism: SES partially influences SE through social capital.

In practice, basing on the conclusion of this research, we should pay more attention to the cultivation and accumulation of SC for those from families with lower SES, provide them with some corresponding assistance, and try to minimize the negative influences caused by low SES.

\section{Conclusion}

Basing on the above analysis and discussion, a summary of the conclusion are as follows:

(1) Family SES as well as all its dimensions (father's degree of education, mother's degree of education, the total annual income of the family, father's occupation, mother's occupation) is significantly positively related to SC and all the dimensions of its proxy variable (peer support, kinship support and general support of others);

(2) There is a significant positive correlation between the family socio-economic status as well as all its dimensions and SE; the socio-economic status, with its dimensions, is the predictive variable of SE;

(3) Social capital, with dimensions of its proxy variable, is positively correlated with SE and has predictive effect on SE

(4) SC plays a significant mediate role between socio-economic status and SE, and the mediating effect size is about $51.75 \%$.

\section{Reference}

Akcomak, S., \& Weel, B. (2009). Social Capital, Innovation and Growth: Evidence from Europe. European Economic Review, 42, 544-567. http://dx.doi.org/10.1016/j.euroecorev.2008.10.001

Bandura, A. (1992). Self-efficacy: Thought Control of Action. London: Hemisphere Publishing Co.

Bian, Y. (2003). The Establishment and Application of the Scale of Perceived Academic Self-efficacy. East China Normal University, Shanghai, China.

Bian, Y., \& Qiu, H. (2000). The Social Capital of Enterprises and Its Efficiency. Social Science in China, 2, 87-99.

Blau, P., \& Duncan, O. D. (1967). The American Occupational Structure. New York: Wiley.

Bolger, K. E. (1995). Psychosocial Adjustment among Children Experiencing Persistent and Intermittent Family Economic Hardship. Child Development, 66, 1107-1129. http://dx.doi.org/10.2307/1131802

Cao, Z. (2003). Sociological Studies, Peasant laborers' Reconstruction of Social Network and the Flow Direction of Domestic Resources. Sociological Studies, 3, 99-110.

Chen, X. (2011). The General Self-efficacy Students, Personality Characteristics and Career Aspirations of the Relevant Research. Harbin Engineering University, Harbin, China.

Chen,Y., \& He, Y. Q. (2011). The impact of strongest on entrepreneurial intention. Journal of Chinese Entrepreneurship, 3(2), 147-158. http://dx.doi.org/10.1108/17561391111144573

Collins, W. A. (1990). Parent - child relationships in the transition to adolescence: Continuity and change in interaction, affect and cognition. In Montemayor, R., Adams, G. R., \& Gullotta, T. P. (Eds), advances in adolescent development : From childhood to Adolescence : A transitional period, 85-106, Newbury Park, CA: Sage.

Deng, W., Lin, Y., \& Gong, J. (2012). A Smooth Coefficient Quintile Regression Approach to the Social Capital-economic Growth Nexus, Economic Modeling, 25,185-197. http://dx.doi.org/10.1016/j.econmod.2011.09.008

Dishion, T. J. (1990). The Family Ecology of Boys' Peer Relations in Middle Childhood. Child Development, 61, 874-982. http://dx.doi.org/10.2307/1130971 
Duncan, O. D. (1961). A socio-economic index for all occupation and Properties and characteristics of the socioeconomic index. Occupations and Social Status. Glencoe: Free Press.

Fleischer, N. L., Diez, R. A., \& Alazraqui, M., et al. (2008). Social patterning of chronic disease risk factors in a Latin American city. J Urban Health, 85(6), 923 -937. http://dx.doi.org/10.1007/s11524-008-9319-2

Galina, M. A. (1984). Social Psychology, translated by Li Zhao et al. Shanghai: Shanghai Translation Publishing Company, 69.

Gao, S. (2000). The Comment on the Theory of Self-efficacy. Psychological Development and Education. (1), 60-63.

Green, L. W. (1970). Manual for scoring socioeconomic status for research on health behavior. Public Health Reports, 85(9), 815-827. http://dx.doi.org/10.2307/4593972

Guiso, L., Sapienza, P., \& Zingales, L. (2004). The Role of Social Capital in Financial Development. American Economic Review, 94, 526-556. http://dx.doi.org/10.1257/0002828041464498

Haller, A. O., \& Portes, A. (1973). Status attainment process. Sociology of Education, 46, 51-91. http://dx.doi.org/10.2307/2112205

He, Z. (2002). Socioeconomic Status and Social Support Network of Rural Elderly and Their Physical and Mental Health. Social Sciences in China, 3, 135-148.

Hollingshead. (1957). Two factor index of social position. New Haven: Department of Sociology, Yale University.

Hu, B., Yang, H., \& Zhu, Y. (2013). An Empirical Study on the Relationship Between Entrepreneurial SC and self-efficacy. Science \& Technology Progress and Policy, 30(10), 12-15.

Hu, P., \& Wang, Z. (2009). Study on the Status and Characteristics or Social Support for Left-home Students in High Middle School and Its Relationship with General Self-efficacy. China Journal of Health Psychology ,11, 1365-1367.

Huang, J., \& Xia, E. (2010). The Analysis of the Influence of Socioeconomic Status on the Health Conditions of Urban Labor Force. Commercial Times, 30, 14-17.

Kaneda, T., Zimmer, Z., \& Tang, Z. (2005). Socioeconomic status differentials in life and active life expectancy among older adults in Beijing. Disabil Rehabil, 27(5), 241-251. http://dx.doi.org/10.1080/09638280400006481

Kathryn, R. W. (1998). Social relationships and motivation in middle school: the role of parents, teachers and peers. Journal of educational psychology, 90(2), 202 - 209. http://dx.doi.org/10.1037/0022-0663.90.2.202

Knack, S., \& Keefer, P. (1997). Does Social Capital Have an Economic Impact? A Cross Country Investigation. Quarterly Journal of Economics, 112, 1251-1288. http://dx.doi.org/10.1162/003355300555475

Kuppuswamy, B. (1981). Manual of socioeconomic status (urban) [M] New Delhi: Manasayan, 28.

Li, C. (2005). The Reputation Hierarchy of Modern Chinese Society - Index Measurement of Occupational Reputation and Socioeconomic Status. Sociology Study, 2, 74-102.

Li, D. (2009). Review the Foreign Research on the Effects of Low Socioeconomic Status on Child Development. Studies in Preschool Education, 3, 10-13.

Li, X. (2003). The Study of the Family Factors Influence on Middle School Students Self-efficacy. Suzhou University, Suzhou, China.

Liu, J. (2009). Locus of Control and Self-efficacy in Workers Holding Low-paying and Low-skilled Jobs. Chongqing University, Chongqing, China.

Liu, L., \& Tang, J. (2004). Research of socioeconomic status effects health disparity. Chinese Health Economics, 6, 40-42.

Liu, S. (2009). The Longitudinal Research on Development of Peer Relationship in Preschool. East China Normal University, Shanghai, China.

Liu, T. (2009). Research on the Relationship between College Students Self-concept, Interpersonal Relationship and Subjective Well-being. Liaoning Normal University, Liaoning, China.

Ma, Y., \& Zhang, B. (2011). The Review of Progress on Measurement of Socioeconomic Status. Chinese Journal of Health Education, 5, 372-382.

McLaren, L. (2007). Socioeconomic status and obesity. Epidemiologic Reviews, 29, 29-48. http://dx.doi.org/10.1093/epirev/mxm001 
NICHD. (2004). Early Child Care Research Network. Trajectories of physical aggression from toddler hood to middle childhood. Monographs of SRCD, 69(278), Serial.

Oakesa, J. M., \& Rossib, P. H. (2003). The measurement of SES in health research: current practice and steps toward a new approach. Social Science \& Medicine, 56, 769-784. http://dx.doi.org/10.1016/S0277-9536(02)00073-4

Patterson, C. J., Kupersmidt, J. B., \& Vaden, N. A. (1990). Income level, gender, ethnicity, and household compositions as predictors of children's school- based competence. Child Development, 61, 485-494. http://dx.doi.org/10.2307/1131109

Pei, Z. (2013). The Effects of Social Capital and Political Efficacy on Villagers' Participation of Self-governance When the Institutions Are Given. Issue of Agriculture Economy, 5(111), 33-43.

Qi, L., \& Wang, C. (2010). Health and Socioeconomic Status: A Research Based on Multiple Indicators. Chinese Health Economics, 8, 47-50.

Rao, H. (2004). Impact of the Family Factors on College Students' Depression and Alienation. Psychological Development and Education, 75.

Ren, C. (2010). Measurement Methodology on Social Economic Status Index of Students. Journal of Educational Studies, 5, 77-82.

Rubin, K., Bukowski, W., \& Parker, J. G. (1998). Peer interactions, relationships and groups. In W. Damon \& N. Eisenberg (Eds.), Handbook of child psychology, Social, Emotional and Personality development, New York: Wiley, 3, 619 -700.

Shi, B., \& Shen, J. (2007). The Relationships among Family SES, Intelligence, Intrinsic Motivation and Creativity. Psychological Development and Education, 1, 30-34

Sun, Z. (1999). A Research on Socioeconomic Status of Families with School Failure Problem. Tsinghua Journal of Education, 1, 47-51.

Temple, J., \& Johnson, P. (1998). Social Capability and Economic Growth. Quarterly Journal of Economics, 113, 967-990. http://dx.doi.org/10.1162/003355398555711

Tianjin Peoples Publishing House. (2004). The Development of Social Psychology in China. Tianjin: Tianjin Peoples Publishing House, 154.

Tiwari, S. C., \& Kumar A. (2005). Development and standardization of a scale to measure socio- economic status in urban and rural communities in India.Indian J Med Res, 122, 309-314.

Tsioufis, C., Kyvelou, S., \& Tsiachris D, et al. (2011). Relation between physical activity and blood pressure levels in young Greek adolescents: The Leontio Lyceum Study. Eur J Public Health, 21(1), 63-68. http://dx.doi.org/10.1093/eurpub/ckq006

Wang, C. (2000). Flowing Social Network: Wenzhou People's Pattern of Actions in Paris and Beijing. Sociological Studies, 3, 109-123.

Wang, Y., \& Tong, X. (2004). A Study of Social Support Network of Flowing Farmers.. Sociological Studies, (2), 42-48.

Warner. (1949). Social Class in America. Chicago: Science Research Associates.

Wight, R. G., Bottcello, A. L., \& Aneshensel, C. S. (2006). Socioeconomic context, social support, and adolescent mental health: A multilevel investigation. Journal of Youth and Adolescence, 35, 115-126. http://dx.doi.org/10.1007/s10964-005-9009-2

Wo, J. (2001). A Research on the Development Characteristics of Social Support to Middle School Students[J], Psychological Development and Education, 3, 9-15.

Woodward, L. J., \& Fergusson, D. M. (1999). Childhood Peer Relationship Problems and Psychosocial Adjustment in Late Adolescence. Journal of Abnormal Child Psychology, 1, 87-104 http://dx.doi.org/10.1023/A:1022618608802

Xin, Z., Chi, L., Geng, L., Zhao, X., \& Wang, J. (2007). Revision and Application of the Social Support Appraisal Scale. Chinese Mental Health Journal, 6, 379-381.

Xu, D. (2011). A Correlational Study on Self-efficacy and Employment Intension of Private College Students. Nanjing Normal University, Nanjing, China.,

$\mathrm{Xu}$, H. (2011). The Relationship among Professional Commitment, Self-Efficacy and Academic Burnout of Postgraduate Students in Research Institutes. East China Normal University, Shanghai, China.,

Yang, Y., \& Hu, B. (2011). Research on Relationship between Social network, Entrepreneur Self- efficacy and 
Entrepreneurship Intention. Soft Science, 6, 59-63.

Ye, H. (1998). History and Systems of Western Psychology. Beijing: People's Education Press.270

Yu, T. (2011). Studies of the Correlation between Socioeconomic Status and Happiness. Jilin University, Jilin, China.

Zak, P., \& Knack, S. (2001). Trust and Growth. Economic Journal, 111, 295-321. http://dx.doi.org/10.1111/1468-0297.00609

Zhang, C. (1994). Modern Psychology. Shanghai: Shanghai People's Publishing House, 143.

Zhang, L. (2008). The Impact Way of Family s Social Economic Status on Senior Students Peer Relationship and Educational Enlightenment. University Of Science and Technology of Hunan, Hunan, China.

Zhang, S., \& Chen, F. (2012). Social Capital and Social-Economic Identity among Urban Residents. Journal of Xi'an Jiaotong University (Social Sciences), 32(3), 95-100.

Zhang, W., \& Ruan, D. (1999). Social Support Network of Urban and Rural Residents. Sociological Studies, 3, 110-111.

Zhang, W., Li, D., \& Xie, Z. (2007). Low Socioeconomic Status and Child Development. Journal of South China Normal University (Social Science Edition), 6, 104-112.

Zheng, Q., \& Yu, G. (1999). Psychology of Social Support. Beijing: People's Education Press.

Zhou, G., Liu, X., Li, L., \& Wang, J. (1994). An analysis on Junior Middle School Students' Ability Self-efficacy. Theory and Practice of Education, 5, 49-51.

\section{(cc) BY}

This work is licensed under a Creative Commons Attribution 3.0 License. 